\title{
The Empirical Analysis of Index Effect in Chinese Stock Market: Based on the SHSZ 300 Index
}

\author{
Yanan $\mathrm{He}^{1}$ \& Zongjun Wang ${ }^{1}$ \\ ${ }^{1}$ School of Management, Huazhong University of Science and Technology, China \\ Correspondence: Yanan He, Huazhong University of Science and Technology, Wuhan, China. E-mail: \\ Nancy_hyn@outlook.com
}

Received: February 9, 2015

Accepted: April 3, 2015

Online Published: April 20, 2015

doi:10.5539/ijbm.v10n5p182

URL: http://dx.doi.org/10.5539/ijbm.v10n5p182

\begin{abstract}
Index effect is an abnormal phenomenon in the security market. It is contrary to the efficient market hypothesis $(\mathrm{EMH})$ and has been well-observed in mature markets. As an emerging market, China plays a more and more essential role in the world. In 2005, first composite index-the SHSZ 300 Index, which combines Shanghai and Shenzhen stock markets was launched in China and got the chasing of investors since then. We attempt to find the performance of index effect in this newly index and we are interested in whether this so-called composite index is more perfect than the traditional single-market index in China or not. Furthermore, we will determine the stage of development of Chinese stock market with an international perspective.

The result exhibits that the SHSZ 300 Index has a significant index effect around announcement date (AD) and relatively weak index effect on effective date (ED), corresponded with the price pressure hypothesis. Investors can make extra profit from this effect. In the meantime, this composite index shows its superiority compared to single-market index for showing the entire stock market. On the other hand, it is still at the early stage compared with the mature market all over the word.
\end{abstract}

Keywords: index effect, the SHSZ 300 Index, empirical analysis, 2005-2013, comparison

\section{Introduction}

Index effect is an anomaly of stock market when the shares are added to or deleted from the index, stock prices and trading volume tend to rise or fall sharply in the short term, so as to form an arbitrage opportunity for investors. As an important category of behavioral finance research, to understand the index effect impact on the abnormal returns of constituent stocks is extremely beneficial for learning the operation of the security market and the investors' behavior.

Foreign scholars research on this topic earlier, while domestic researchers just begin. Based on recent decades' literature, there exists the index effect in the stock market all over the world, especially in the mature market. Investors can obtain abnormal returns and their concerns about the degree of indexation will further enhance this effect.

With the development of Chinese stock market, especially mutual fund, social security, insurance fund and QFII, institution investors are becoming a more important role and index investing is also getting popular. In 2005, China has launched the SHSZ 300 index, which is China's first composite index across the Shanghai and Shenzhen stock market. It can fully show the stock market and is the only index futures in China. Inventors are wondering if this composite index is better than single index (like SSE 150, SZSE); if it has index effect and whether they can utilize this to make abnormal returns.

We make an empirical study on the index effect of the SHSZ 300 Index which covered nine-year period through June 2005 to December 2013 and 677 sample stocks in total. The purposes of this research are as follows:

(1) To examine the existence of index effect and arbitrage space of the SHSZ 300 Index; (2) To explore the price effect of additions/deletions; (3) To analyze whether the SHSZ 300 index is more composite than other traditional indexes in China; (4) To determine the development stage of Chinese stock market.

This article will provide country based study and enrich the researches of index effect all over the world. It also makes the results of index effect of the SHSZ 300 Index more reliable due to the more comprehensive data 
(9-years). Moreover, we use empirical study around two event dates - the announcement date and effective date - to show a relative complete index effect of Chinese stock market.

\section{Literature Review}

\subsection{Studies on Global Perspective}

Shleifer (1986) is the first scholar who starts this research. He uses the data from 1976 to 1983 of S\&P 500 index before and after the adjustment and finds that price of additions rise up while the deletions are fallen down, along with significant trading volume amplification before announcement. Harris and Gurel (1986) use the similar sample but make a different conclusion. They find that the new stocks added in the S\&P 500 index turn out to a $3.13 \%$ abnormal return, while the stocks deleted out from the index is $-1.4 \%$. They also point out that the price effect arisen by index adjustment will be returned to the original level around two weeks after the effective date. This is the price pressure hypothesis advanced by them and is the only theory that predicts a temporary increase in the price of a newly-added stock. Beneish and Whaley (2002) study the constituent stocks' adjustment of the S\&P 500 index through 1986 to 1996 and discover that the stock prices rise abnormally since the announcement day. When the constituent stocks are actually added in the index, the reaction of prices reverse with a little degree respect to the announcement date. They believe that it is a signal for speculators who will purchase the shares before the index funds then sale them out when stock prices rise to make a profit after they get this information. Lynch and Mendenhall (1997) make an empirical study about index effect of changing adjustment rule by constructing trading strategy. They discover that the stocks are added in the S\&P 500 index will produce an average abnormal returns of $3.8 \%$, while the deletions occur an negative abnormal returns.

In addition, foreign scholars study this topic about other indexes of United States. Beneish and Gardner (1995) study the US DJIA index and the results show that the additions have no significant positive abnormal returns but deletions have evidently negative abnormal returns. Breazeale and Cuny (2002) who research on the S\&P 500 Mid-Cap 400 index and the S\&P 500 Small-Cap 600 index find a similar conclusion as Breazeale and Cuny do.

A growing number of scholars from the rest of the world analyzed index effect of their own countries in recent years and the results extremely worth our attention. Brealey (2000) studies the index effect of the British's FTSE 100 index; Deininger et al. (2000) make a research on the German DAX and MDAX index adjustments; Kaul \& Mehrotra (2000) study on the TSE 300 index; Clause (2000) researches DAX index of German; Liu (2001) studies the effect of adjustment for the Japanese Nikkei 500 index; As for New Zealand market, Elayan, Li et al. (2001) research the NZSE index. All studies show that the index effect is widespread in stock market while the degree of expression and the performance are observably different. The performance not only has various distinct market characteristics, but also has a markedly relationship with the development stage of the national stock market.

In conclusion, scholars make a large number of researches about mature markets and find the index effect exists commonly, while studies on emerging markets like China are relatively less.

\subsection{Studies on Chinese Perspective}

Domestic scholars began these studies since 2000 and it's still in early stage. But this topic has caused more and more concerns. In China, Shanghai Stock Exchange and Shenzhen Stock Exchange have successively developed its own index products separately which all play a significant role in the whole market. Liu Bincai (2004) investigates the index effect of the first adjustment of the Shanghai Composite 180 index by event study and finds an abnormal returns rate about $-1.23 \%$ at the effective date. The cumulative abnormal returns gradually decrease after the adjustment. Qiu Xiaofeng and Xu Jiangang (2004) study the effect of early adjustments of Shenzhen Component index, find that on the adjustment date, additions have markedly abnormal returns of $1.30 \%$, accompanied by a large abnormal trading volume. Song Fengming and Wang Chunyan (2005) have an empirical study on the Shanghai Composite 180 index and the Shenzhen Component Index. They define that no regular index effect occurs and the impact of it is short-term. As for Shanghai Composite 50 index, the expected abnormal returns emerge at effective date when constituent stocks are added in or deleted out of the index (Wang Xiaojing, 2006). Zhang Jiangang and Zhang Wei (2007) research the Shanghai Composite 180 index and get that additions produce lasting positive abnormal returns while deletions occur reversal of abnormal returns. To conclude, index effect of single-market is not stable, while those results have significance for a comprehensive understanding of the index effect in China.

As index covering the two markets-Shanghai and Shenzhen — does not have a long history, the index effect of it may have special characteristics which worth to be studied. Since the SHSZ 300 Index was launched in June 
2005, domestic scholars change their research direction to here. Yuan Kun (2010) defines a significant Announcement Effect on the SHSZ 300 Index from January 2005 to November 2008. Shen Haiping and Qiu Haifeng (2012) who use the event study method and data of January 2010 find that the SHSZ 300 Index shows an obvious index effect in the background of index futures launched. Liu Wenjuan (2012) does the research and finds short-term price effect exists evidently, but the long-term effect is not obvious, corresponding to the price pressure hypothesis. Chen Jianan \& Jiang Wei (2012) select 3 times adjustments from June 2010 to June 2011, and determine this index has a markedly price and volume effects.

In summary, domestic scholars' researches primarily depend on the foreign hypothesis and preliminary verdict the existence of index effect in the SHSZ 300 Index. Before 2005, scholars focused on individual markets, which are not able to represent the whole Chinese stock market. While the period is not long enough to include all data and gives reliable results for researches on the SHSZ 300 Index. This paper selects event study method to research on this topic and analyzes two event dates, as well as adjustment data of 9 years to explore the existence of index effect and arbitrage space of the SHSZ 300 Index. Then we compare the differences of our results between single market index and mature market index.

\section{Data and Methodology}

\subsection{Research Sample}

The SHSZ 300 Index can reflect the overall trend of A-share market, which is issued by Shanghai and Shenzhen Stock Exchange. The market capitalization is about $65 \%$ in the total market capitalization and net profit is more than $80 \%$ of the total listed companies' profits. It may show the change of stock price and the overall operation of Chinese securities market.

The SHSZ 300 Index has twice periodic adjustments every year (generally on June \& December). When special events occur, which affects the representation and investment of the index (such as bankruptcy, merger or delisting), temporary adjustments will be made by China Securities Index Co., Ltd.. In the period of our research, there are 18 times periodic adjustments and 17 times temporary adjustments happened.

Detail of periodic adjustments and temporary adjustments are listed in Table 1 and Table 2.

Table 1. Periodic adjustments of the SHSZ 300 index

\begin{tabular}{lllllllll}
\hline $\mathrm{AD}$ & $2005 / 6 / 22$ & $2005 / 12 / 20$ & $2006 / 6 / 12$ & $2006 / 12 / 11$ & $2007 / 6 / 11$ & $2007 / 12 / 10$ & $2008 / 6 / 4$ & $2008 / 12 / 15$ \\
\hline $\begin{array}{l}\text { Number of } \\
\text { Adjustments }\end{array}$ & 14 & 14 & 30 & 30 & 28 & 30 & 19 & 18 \\
$\mathrm{AD}$ & $2009 / 6 / 15$ & $2009 / 12 / 14$ & $2010 / 6 / 17$ & $2010 / 12 / 13$ & $2011 / 6 / 13$ & $2011 / 12 / 12$ & $2012 / 6 / 11$ & $2012 / 12 / 17$ \\
$\begin{array}{l}\text { Number of } \\
\text { Adjustments }\end{array}$ & 24 & 16 & 18 & 26 & 23 & 24 & 18 & 15 \\
AD & $2013 / 6 / 17$ & $2013 / 12 / 02$ & & & & & & \\
$\begin{array}{l}\text { Number of } \\
\text { Adjustments }\end{array}$ & 16 & 21 & & & & & & \\
\hline
\end{tabular}

Table 2. Temporary adjustments of the SHSZ 300 index

\begin{tabular}{|c|c|c|c|c|c|c|c|c|}
\hline $\mathrm{AD}$ & $2006 / 4 / 14$ & $2006 / 7 / 6$ & $2006 / 8 / 2$ & $2006 / 10 / 18$ & $2007 / 1 / 10$ & $2007 / 2 / 6$ & $2007 / 3 / 2$ & $2007 / 4 / 27$ \\
\hline $\begin{array}{l}\text { Number of } \\
\text { Adjustment }\end{array}$ & 4 & 1 & 1 & 1 & 1 & 1 & 1 & 2 \\
\hline Adjustment Reason & Purchase & New shares & New shares & New shares & New shares & New shares & New shares & Purchase \\
\hline $\mathrm{AD}$ & $2007 / 4 / 30$ & $2007 / 5 / 16$ & $2007 / 10 / 10$ & $2007 / 11 / 6$ & $2007 / 12 / 25$ & $2008 / 3 / 10$ & $2009 / 12 / 22$ & $2011 / 8 / 5$ \\
\hline $\begin{array}{l}\text { Number of } \\
\text { Adjustments }\end{array}$ & 1 & 1 & 1 & 1 & 1 & 1 & 2 & 1 \\
\hline Adjustment Reason & New shares & New shares & New shares & New shares & Delisting & Delisting & Purchase & Purchase \\
\hline $\mathrm{AD}$ & $2013 / 8 / 13$ & & & & & & & \\
\hline $\begin{array}{l}\text { Number of } \\
\text { Adjustments }\end{array}$ & 1 & & & & & & & \\
\hline Adjustment Reason & Delisting & & & & & & & \\
\hline
\end{tabular}

Through this period, there occur 768 additions and deletions in total. To obtain accurate results, we construct a 
complete sample, which eliminates some observations from the original sample for reasons like samples are undergoing merger,spin-off or takeovers. The final complete sample of additions consists of 340 stocks and the sample of deletions consists of 337 stocks. Table 3 shows the detail.

Table 3. Adjustment time \& number of the SHSZ 300 Index from June 2005 to January 2014

\begin{tabular}{lllllll}
\hline & AD & ED & Addition & Excluding & Deletion & Excluding \\
\hline \multirow{6}{*}{ 2005.06.22 } & 2005.07 .01 & 14 & - & 14 & - \\
& 2005.12 .20 & 2006.01 .01 & 14 & 2 & 14 & 2 \\
& 2006.06 .12 & 2006.07 .03 & 30 & 2 & 30 & 1 \\
& 2006.12 .11 & 2007.01 .14 & 30 & 1 & 30 & 3 \\
& 2007.06 .11 & 2007.07 .02 & 28 & 3 & 28 & 2 \\
& 2007.12 .10 & 2008.01 .02 & 30 & 2 & 30 & 2 \\
& 2008.06 .04 & 2008.07 .02 & 19 & 3 & 19 & 4 \\
& 2008.12 .15 & 2009.01 .06 & 18 & 5 & 18 & 2 \\
& 2009.06 .15 & 2009.07 .02 & 24 & 4 & 24 & 3 \\
Periodic & 2009.12 .14 & 2010.01 .04 & 16 & 2 & 16 & 2 \\
& 2010.06 .17 & 2010.07 .01 & 18 & 2 & 18 & 3 \\
& 2010.12 .13 & 2011.01 .04 & 26 & 5 & 26 & 4 \\
& 2011.06 .13 & 2011.07 .01 & 23 & 4 & 23 & 5 \\
& 2011.12 .12 & 2012.01 .04 & 24 & 3 & 24 & 4 \\
& 2012.06 .11 & 2012.07 .02 & 18 & 2 & 18 & 3 \\
& 2012.12 .17 & 2013.01 .04 & 15 & 2 & 15 & 3 \\
& 2013.06 .13 & 2013.07 .01 & 16 & 1 & 16 & 2 \\
Total & 2013.12 .02 & 2013.12 .16 & 21 & 1 & 21 & 2 \\
\hline & & & 384 & 44 & 384 & 47 \\
\hline
\end{tabular}

\subsection{Methodology}

We use event study method with two event dates: The announcement date (AD), which is the adjustment announcement published on the official website, and the effective date (ED) when the announcement is carried out. As the minimum and maximum of time interval between AD and ED are not the same each adjustment, we must distinguish announcement date and effective date according to the time point. In order to calculate the expected rate of return of the sample stock, we determine the estimation window is 60 th trading day to the 11 th trading day before the announcement $([-60,-11])$ - a total of 50 days. As we have two event dates, we have two event windows as well. They are the 10th trading day before the announcement to 10th trading day after AD $([-10,10])$, as well as day -5 to day +5 based on the ED $([-5,5])$.

\subsection{Variables}

This article includes three variables: normal return, abnormal returns and statistical tests.

\subsubsection{Normal Returns}

We use the CAPM model to estimate the stock's normal returns, the formula is as follows:

$$
R_{i t}-R_{f t}=\alpha+\beta\left(R_{m t}-R_{f t}\right)+u_{t}
$$

For day t, Rit represents rate of return of stock i; Rft is the risk-free interest rate (we select three-year fixed deposit interest here); $\alpha$ is the intercept, which means the difference between the risk-free interest rate and stock $i$ when stock i's system risk is zero; Rmt is the market returns at time $t ; \beta$ measures system risk for stock $i, \mu t$ is the residual.

\subsubsection{Abnormal Returns}

Abnormal returns are difference between actual return and normal return, the formula is:

$$
A R_{i t}=R_{i t}-R_{f t}-\left[\hat{\alpha}+\hat{\beta}\left(R_{m t}-R_{f t}\right)\right]
$$

In this formula ARit is used to represent abnormal returns for the stock $i$ at time $t ; \alpha$ and $\beta$ are the estimated 
values in the estimation window. To examine the overall changes in stock returns, we define the following variables and formulas:

$$
\begin{aligned}
& A A R_{t}=\frac{1}{N} \sum_{i=1}^{N} A R_{i t} \\
& \operatorname{CAR}_{i t}=\sum_{i=t}^{T} A R_{i t} \\
& \text { CAAR }_{t}=\frac{1}{N} \sum_{i=1}^{N} C A R_{i t}
\end{aligned}
$$

In above formulas, AARt is average abnormal returns for all stocks at time $\mathrm{t}$; $\mathrm{N}$ is the number of samples; CARit is cumulative abnormal returns for stock $i$ from time $t$ to time $T(T \geqslant t)$; CAARt represents average cumulative rate of return for all sample stocks from time $t$ to $\mathrm{T}$.

\subsubsection{Statistical Tests}

For the sake of observing whether the sample stocks have significant changes due to add to or delete from the index, we need to test the cumulative abnormal returns during the event and we select $\mathrm{T}$ test to analyze. Hypothesis testing of cumulative abnormal return are as follows:

H0: CARt $=0$,

$\mathrm{H} 0$ represents the adjustment which has no effect on the stock prices and the changes of CAR are random walk.

H1: CARt $\neq 0$,

H1 shows that changes of share prices are not random and adjustment has a notable impact on stock prices.

T-test for cumulative abnormal returns is:

$$
T_{C A R}=\frac{C A R_{t}}{S\left(C A R_{t}\right) / n}: t(n-1)
$$

\section{Results Analysis}

The impact of the index effect on company's stock is mainly reflected in two aspects: the price and trading volume. This article will focus on the price effect.

\subsection{Index Effect on the $A D$}

We use SPSS 13.0 to test all sample stocks' abnormal returns around adjustment announcement date. The results of effect on the AD are shown in Figure 1, Figure 2 and Table 4 and the performance of the index effect is quite stable.

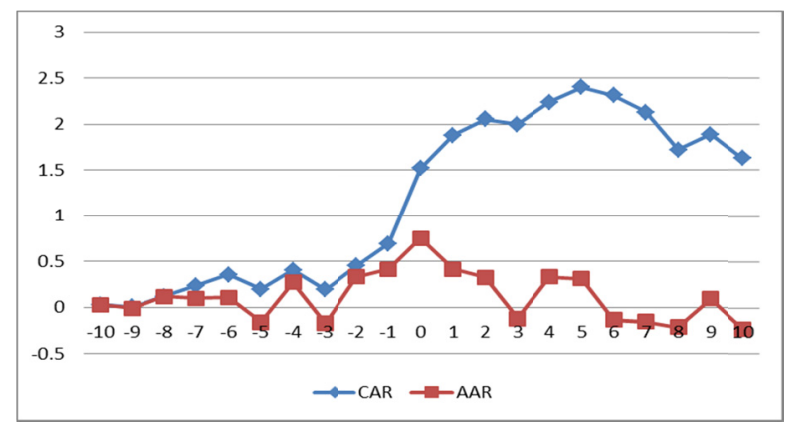

Figure 1. Changes of abnormal returns for additions on $\mathrm{AD}$

Since the 3rd day before the $\mathrm{AD}$, additions show volatility and evidently positive abnormal returns. The cumulative abnormal returns are increasing and basically at $10 \%$ significant level. It indicates that the market reflects a short-term advance reaction for the underlying shares added to the SHSZ 300 Index. On the AD, the prices of additions appear abnormal volatility and the CAR reaches $1.52 \%$. The average abnormal returns maintain positive after the $\mathrm{AD}$, whereas the cumulative abnormal returns arrive at its maximum $-2.41 \%$ - of the 
entire event window on the 5th day after $\mathrm{AD}$. The main reason is institutional investors tracking the index or adjusting the position will consider purchasing the newly added stocks, which causes many ordinary retail investors to follow the trend of purchasing, therefore the returns of transferred stock is pushed up. Then at the day +6 , the average abnormal return becomes negative from positive, and the cumulative abnormal return reduces. These all suggest that the previous investors sell their shares after they get extra profits. Then the prices of stock deduct and this will let slow-response investors risky a lot.

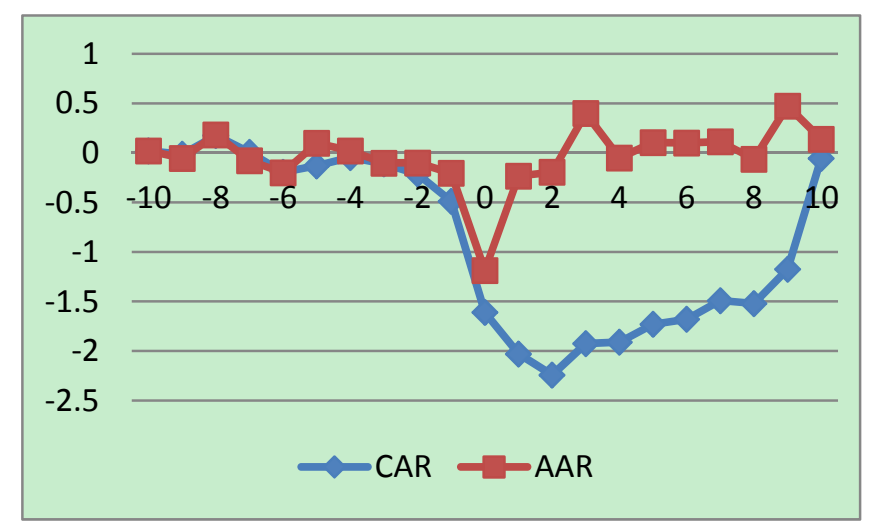

Figure 2. Changes of abnormal returns for deletions on $A D$

As for deletions, although the result shows that the significance of index effect is slightly lower than additions', it still can arrive at the $10 \%$ significant level. During the day -10 to day -4 , the returns have no markedly movements, as well as the cumulative abnormal returns during this period is close to zero. Nevertheless there comes an increasing volatility and shows an observably negative AAR from the 3rd day ahead the AD. CAR rises at the same time. These all illustrate that a few of investors have already prejudged some constituent stocks may soon be removed from the SHSZ 300 Index and sold them out in advance. At AD, prices of deletions drop down sharply and AAR comes to $-1.19 \%$, the lowest point within the entire event window. Pass through that day, the minimum negative CAR emerges at $-2.24 \%$ in day +2 . From then on, AAR increases from negative to positive and CRA starts recovery, showing that a number of investors begin to bargain intervention after stocks price go down. Thus the prices of deletions increase.

Table 4. Abnormal returns and T-test of sample stocks on AD

\begin{tabular}{lllllll}
\hline Time & $\begin{array}{l}\text { Additions } \\
\mathrm{AAR}_{\mathrm{a}}\end{array}$ & $\mathrm{CAR}_{\mathrm{a}}$ & $\mathrm{T}_{\mathrm{a}}$ & $\begin{array}{l}\text { Deletions } \\
\mathrm{AAR}_{\mathrm{d}}\end{array}$ & $\mathrm{CAR}_{\mathrm{d}}$ & $\mathrm{T}_{\mathrm{d}}$ \\
\hline $\mathrm{AD}-10$ & $0.03110 \%$ & $0.03110 \%$ & 0.20736 & $0.02112 \%$ & $0.02112 \%$ & 0.31788 \\
$\mathrm{AD}-9$ & $-0.01121 \%$ & $0.00191 \%$ & 0.09851 & $-0.05544 \%$ & $-0.01308 \%$ & 0.07841 \\
$\mathrm{AD}-8$ & $0.11820 \%$ & $0.11854 \%$ & 0.11204 & $0.18388 \%$ & $0.17667 \%$ & 0.21540 \\
$\mathrm{AD}-7$ & $0.09750 \%$ & $0.09786 \%$ & 0.07413 & $-0.07811 \%$ & $0.00563 \%$ & 0.16411 \\
$\mathrm{AD}-6$ & $0.11060 \%$ & $0.11281 \%$ & 0.08576 & $-0.20133 \%$ & $-0.19550 \%$ & 0.09337 \\
$\mathrm{AD}-5$ & $-0.15932 \%$ & $0.19767 \%$ & 0.02843 & $0.09821 \%$ & $-0.13322 \%$ & 0.07344 \\
$\mathrm{AD}-4$ & $0.27230 \%$ & $0.40670 \%$ & 0.06411 & $0.02158 \%$ & $-0.04619 \%$ & 0.08924 \\
$\mathrm{AD}-3$ & $-0.10320 \%$ & $0.19177 \%$ & 0.04271 & $-0.10355 \%$ & $-0.11430 \%$ & 0.03538 \\
$\mathrm{AD}-2$ & $0.33110 \%$ & $0.45320 \%$ & 0.05432 & $-0.10121 \%$ & $-0.21267 \%$ & 0.04687 \\
$\mathrm{AD}-1$ & $0.41630 \%$ & $0.69211 \%$ & 0.03969 & $-0.20488 \%$ & $-0.48901 \%$ & 0.04125 \\
$\mathrm{AD}$ & $0.75120 \%$ & $1.51893 \%$ & 0.02076 & $-1.18660 \%$ & $-1.61004 \%$ & 0.02955 \\
$\mathrm{AD}+1$ & $0.41460 \%$ & $1.87890 \%$ & 0.02778 & $-0.23312 \%$ & $-2.03179 \%$ & 0.03643 \\
$\mathrm{AD}+2$ & $0.32432 \%$ & $2.05421 \%$ & 0.03344 & $-0.19420 \%$ & $-2.24322 \%$ & 0.06412 \\
$\mathrm{AD}+3$ & $-0.12153 \%$ & $1.99789 \%$ & 0.05143 & $0.39919 \%$ & $-0.19256 \%$ & 0.08891 \\
$\mathrm{AD}+4$ & $0.33255 \%$ & $2.23561 \%$ & 0.70350 & $-0.05112 \%$ & $-1.91106 \%$ & 0.07432 \\
$\mathrm{AD}+5$ & $0.31240 \%$ & $2.41111 \%$ & 0.09411 & $0.10459 \%$ & $-1.73110 \%$ & 0.08471 \\
$\mathrm{AD}+6$ & $-0.13560 \%$ & $2.31700 \%$ & 0.10242 & $0.10007 \%$ & $-1.67916 \%$ & 0.07612 \\
$\mathrm{AD}+7$ & $-0.15332 \%$ & $2.12842 \%$ & 0.09441 & $0.11316 \%$ & $-1.49225 \%$ & 0.05879 \\
$\mathrm{AD}+8$ & $-0.21269 \%$ & $1.72360 \%$ & 0.14798 & $-0.06256 \%$ & $-1.52100 \%$ & 0.12250 \\
$\mathrm{AD}+9$ & $0.09462 \%$ & $1.89771 \%$ & 0.17544 & $0.47456 \%$ & $-1.17540 \%$ & 0.08410 \\
$\mathrm{AD}+10$ & $-0.23230 \%$ & $1.63551 \%$ & 0.09211 & $0.13901 \%$ & $-0.05611 \%$ & 0.10399 \\
\hline
\end{tabular}


To summarize, additions have a significant positive abnormal return around AD with a peak of $2.41 \%$, then the cumulative earnings decline at the 5th day after the announcement. Moreover, an evidently negative abnormal return appears to deletions enduring the window and reaches up to $-2.24 \%$ at day +2 . The negative cumulative abnormal returns become narrow around the day +3 . We can also grasp that index effect of the SHSZ 300 Index is temporary as CAR for both additions and deletions go back to normal generally after the AD, and it has arbitrage space. In the meantime, there is a certain symmetry return-curve of additions and deletions. It's obvious that the SHSZ 300 Index has remarkable index effect around AD which consistent with the price pressure hypothesis.

\subsection{Index Effect on the ED}

As mentioned above, for showing a relative complete index effect of Chinese stock market, we also chose the effective date (ED) as the event date to further analysis the characteristics of index effect of the SHSZ 300 Index.

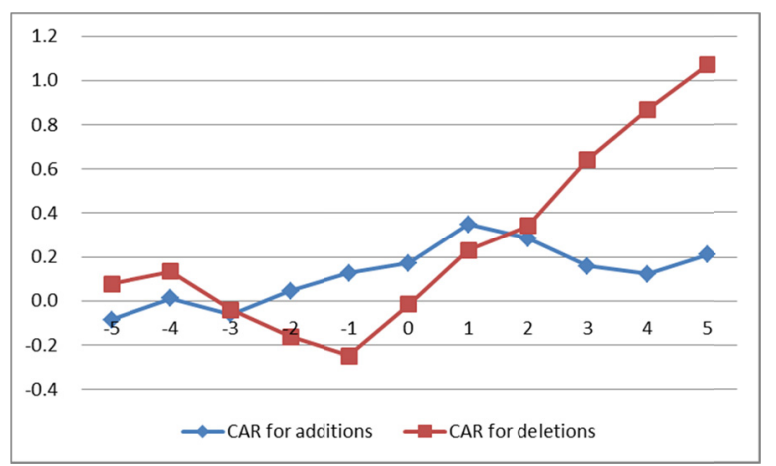

Figure 3. Changes of CAR for additions and deletions on ED

The cumulative abnormal returns for additions and deletions on the ED are plotted in Figure 3 in the window (-5, 5 ) and the detail results are shown in Table 5 below. At the day -5 , there appears a positive cumulative abnormal return of additions. Then the volatility of CAR declines and CAR turns negative on the ED, indicating that several investors purchase additions due to the information of adjustments time which has already been notified. Then prices of additions go down on the ED because investors get profit and sale their shares. Following the ED, the cumulative abnormal returns slightly turn positive, suggesting that the index effect of additions is getting weaker and weaker. Overall, the additions' index effect is not significant around the effective date.

The deletions have negative cumulative abnormal returns from the 5th day to the 1st day before the ED. Then cumulative abnormal returns get narrow, which illustrate that investors are still selling their portfolio a few days before the ED. As position adjustment of index funds have been basically completed with the approaching of adjustment date, as well as other investors in the market have begun to focus on these stocks and purchase gradually, the returns are pulled high. From the ED, cumulative abnormal returns turn from negative to positive and continue raising to a peak of $1.07 \%$ on the day +5 , explaining that the investors begin to bargain intervention before sample stocks are deleted from the SHSZ 300 index due to the large pre-adjustment. It makes cumulative abnormal returns turn positive and index effect impact emerges reversal. It also shows that the SHSZ 300 Index impact on deletions is short-term and its influence will not affect the intrinsic value of these stocks. 
Table 5. Abnormal returns and T-test of sample stocks on ED

\begin{tabular}{ccccccc}
\hline \multirow{2}{*}{ Time } & \multicolumn{3}{c}{ Additions } & \multicolumn{3}{c}{ Deletions } \\
\cline { 2 - 7 } & $\mathrm{AAR}_{\mathrm{a}}$ & $\mathrm{CAR}_{\mathrm{a}}$ & $\mathrm{T}_{\mathrm{a}}$ & $\mathrm{AAR}_{\mathrm{d}}$ & $\mathrm{CAR}_{\mathrm{d}}$ & $\mathrm{T}_{\mathrm{d}}$ \\
\hline ED-5 & $-0.08556 \%$ & $-0.08556 \%$ & 0.23843 & $0.07821 \%$ & $0.07821 \%$ & 0.77414 \\
$\mathrm{ED}-4$ & $0.13723 \%$ & $0.12407 \%$ & 0.08641 & $0.06058 \%$ & $0.13361 \%$ & 0.05799 \\
$\mathrm{ED}-3$ & $-0.10832 \%$ & $-0.06177 \%$ & 0.15427 & $-0.17355 \%$ & $-0.04114 \%$ & 0.06735 \\
$\mathrm{ED}-2$ & $0.08311 \%$ & $0.04532 \%$ & 0.01454 & $-0.12121 \%$ & $-0.16213 \%$ & 0.09847 \\
$\mathrm{ED}-1$ & $0.14630 \%$ & $0.12692 \%$ & 0.07640 & $-0.07488 \%$ & $-0.24890 \%$ & 0.05739 \\
$\mathrm{ED}$ & $0.04751 \%$ & $0.17189 \%$ & 0.05276 & $0.23866 \%$ & $-1.01561 \%$ & 0.03911 \\
$\mathrm{ED}+1$ & $0.17613 \%$ & $0.34879 \%$ & 0.07780 & $0.28312 \%$ & $0.23179 \%$ & 0.04536 \\
$\mathrm{ED}+2$ & $-0.03243 \%$ & $0.28542 \%$ & 0.11334 & $0.09420 \%$ & $0.34271 \%$ & 0.08012 \\
$\mathrm{ED}+3$ & $-0.13853 \%$ & $0.15789 \%$ & 0.06246 & $0.30909 \%$ & $0.64382 \%$ & 0.10879 \\
$\mathrm{ED}+4$ & $-0.05326 \%$ & $0.12356 \%$ & 0.05035 & $0.21513 \%$ & $0.86911 \%$ & 0.13743 \\
$\mathrm{ED}+5$ & $0.10988 \%$ & $0.21111 \%$ & 0.11411 & $0.18605 \%$ & $1.07031 \%$ & 0.07702 \\
\hline
\end{tabular}

Through the study above, we get the conclusion that additions and deletions show a positive and a negative CAR respectively, which is similar to the results we gain from index effect on $\mathrm{AD}$. It indicates that index effect exists around the ED. However, abnormal returns of deletions occur evidently reversal and gain a $1.07 \%$ abnormal return which passes through $10 \%$ significant level on the 5th day after the ED. Although the additions portfolios make a $0.21 \%$ CAR on the same day, it's obviously weaker than the deletions'.

\subsection{Compare to Domestic Single-Market Indexes}

Domestic scholars have observed indexes of Shanghai or Shenzhen such as Shanghai Composite 180 Index (SSE 180), Shenzhen composite Index (SZSE) since 2002 and all results reveal that index effect does not exist in these indexes. For example, Song Fengming \& Wang Chunyan (2005) from School of Economics and Management of Tsinghua University choose over 4 times adjustment of the SSE180 Index (the results are shown in Table 6) and find that all additions' $\mathrm{AAR}$ arrive at $-0.21 \%$ at $\mathrm{AD}$, and there is no markedly different from zero for AAR. On the other side, the AAR on the effective date was $0.03 \%$, which does not show significance either. For deletions, the performance of its index effect is not acutely stable. Deletions have an AAR of $-0.43 \%$, less than zero at $5 \%$ significant level on the AD. From a historical point of view, the index effect is not remarkable.

Table 6. The price effect of the Shanghai composite 180 index

\begin{tabular}{lllllll}
\hline & \multicolumn{3}{l}{ Additions } & \multicolumn{5}{l}{ Deletions } \\
\cline { 2 - 7 } & Sample & AAR & T & Sample & AAR & T \\
\hline Samples on AD & 69 & -0.21 & -0.377 & 71 & $-0.43^{* *}$ & -2.293 \\
Samples on ED & 69 & 0.03 & 0.156 & 71 & $0.48^{* * *}$ & 1.709 \\
First Adjustment on AD & 17 & 0.34 & $1.780^{* * *}$ & 18 & -0.13 & -0.346 \\
First Adjustment on ED & 17 & -0.008 & -0.015 & 18 & 0.8 & 1.252 \\
Second Adjustment on AD & 18 & -1.9 & -0.915 & 17 & -0.03 & -0.116 \\
Second Adjustment on ED & 18 & -0.07 & -0.233 & 17 & -0.12 & -0.384 \\
Third Adjustment on AD & 16 & -0.11 & -0.249 & 18 & -1.31 & $-6.824^{*}$ \\
Third Adjustment on ED & 16 & -0.41 & -1.147 & 18 & -0.15 & -0.341 \\
Fourth Adjustment on AD & 18 & 0.87 & $2.661^{* *}$ & 18 & -0.33 & -0.612 \\
Fourth Adjustment on ED & 18 & 0.56 & $1.858^{* * *}$ & 18 & 1.21 & $1.775^{* * *}$ \\
\hline
\end{tabular}

Note. $* * *, * *, *$ represents significant level at $10 \%, 5 \%$ and $1 \%$ respectively.

As for Shenzhen Component Index, they selected 5 times adjustments (the results are shown in Table 7). The AAR of additions shows $1.01 \%$ at $1 \%$ significant level, greater than zero, while deletions 'AAR is -0.31 without significance. A sum of stocks of Shenzhen Component Index was adjusted in the first 5 times adjustments, but they find only the 3rd one and 5th one show significance at statistics. Thus the Shenzhen Component Index appears a none-obvious index effect. 
Table 7. The price effect of the Shenzhen component index

\begin{tabular}{lllllll}
\hline & \multicolumn{3}{l}{ Additions } & \multicolumn{3}{l}{ Deletions } \\
\hline & Sample & AAR & T & Sample & AAR & T \\
\hline All Samples on ED & 57 & 1.01 & $2.932^{*}$ & 59 & -0.31 & -0.86 \\
First Adjustment on ED & 16 & 0.38 & 0.807 & 15 & 1.53 & $2.946^{* *}$ \\
Second Adjustment on ED & 8 & 1.92 & 1.419 & 10 & 0.38 & 0.529 \\
Third Adjustment on ED & 10 & 2.62 & $3.305^{*}$ & 10 & -3.74 & -3.325 \\
Fourth Adjustment on ED & 9 & -0.07 & -0.063 & 9 & -0.71 & 1.644 \\
Fifth Adjustment on ED & 5 & 1.82 & $9.206^{*}$ & 6 & -0.73 & $-3.453^{* * *}$ \\
\hline
\end{tabular}

Note. ***, **, * represents significant level at $10 \%, 5 \%$ and $1 \%$ respectively.

Consequently, the SHSZ 300 Index has remarkably advantages compared to single-market index. First of all, the index effect actually exists in it which can assist investors to get extra profit. Secondly, it enriches the index system of the market and it has more constituents stocks which makes it possible for investors to fully grasp the operational state and the overall trend of the market. Moreover, it helps the government and financial authorities to strengthen macro-control and enhance the international competitiveness of Chinese security market. Lastly, for the analysis of the behavior of participants in Chinese capital market, it has a very positive reference.

\subsection{Compare to the Other Indexes of Mature Capital Markets}

By international comparison, we can discover that CAR of additions in the mature markets can generally achieve more than $3 \%$ around the AD, whereas the SHSZ 300 Index only reach $2.34 \%$, which slightly below the average level. The main reason is the development of current domestic index fund and ETF fund are still at a low stage. It is worth noting that as the same major investment indexes of the two great economies - China and American, the difference between them is really huge (As shown in Table 8). The proportion of the total market capitalization held by index funds of the S\&P 500 index is much larger than the SHSZ 300 Index's. In China, the amount of funds tracking the SHSZ 300 Index is only 120 billion, relatively small compared to the 5.52 trillion market capitalization of listed companies of the SHSZ 300. Thus it is difficult to adjust the price of stocks added to the Index. Besides, the Chinese stock market has a multitude of institutional investors currently who are wild with concept stocks or small-cap stocks, which leads to the interests for blue chip stocks - the important part of the index - are relatively small. While in American, holding-share of institutional investors are more than 50\% because investors from mutual funds, pension funds, insurance funds and other institutional make their decision rational and seek for stable profits. So the constituent stocks (blue chip stocks) from the indexes like the S\&P 500 , the NASDAQ or other major indexes are sought after by them. As statistics show, the amount of funds tracking the S\&P 500 index is more than $\$ 1$ trillion. Therefore, when these major indexes occur constituents adjustment, short-term abnormal returns of additions are relatively high.

Table 8. Comparison between the SHSZ 300 index and the S\&P 500 index

\begin{tabular}{lll}
\hline Index & SHSZ 300 index & S\&P 500 index \\
\hline Launched year & 2005 & 1957 \\
Number of Constituent Shares & 300 & 500 \\
Total Market Capitalization of Constituent Shares(\$) & 28312 trillion & 103600 trillion \\
Index Fund Positions(\$) & 187 trillion & 10000 trillion \\
Ratio of Index Fund Positions and the Total MC & $0.66 \%$ & $9,65 \%$ \\
\hline
\end{tabular}

As a result, although the index effect exists in Chinese stock market, especially in the composite index, it still has a large difference between mutual market like the S\&P 500 Index in aspects as market capitalization of constituent shares, index fund positions and holding-shares of institutional investors. While China is an emerging market and is in rapid development now. We believe that the difference will become narrow and narrow in the next decades.

\section{Conclusion and Suggestions}

\subsection{Conclusion}

In our article, the main conclusions are as follows:

(1) The SHSZ 300 Index shows index effect around both AD and ED. Although the abnormal returns of it are not 
considerable, it still can bring profit. However, we only get results for short-term investors. Long-term effectiveness of this strategy needs to be further researched.

(2) The additions show evidently positive abnormal returns before and after the $\mathrm{AD}$, which can achieve the cumulative earnings up to $2.41 \%$ ( passes through significant test). Then CAR declines at the 5 th day after the AD. Deletions appear markedly negative abnormal returns (nearly $-2.24 \%$ ) and negative CAR begin to get narrow in the 3rd day following the AD.

(3) Additions/deletions show positive and negative CAR respectively before ED, which resembles to the results from $\mathrm{AD}$ and reveals that the index effect still exists. However, abnormal returns of the deletions occur an extremely observably reversal after the ED. Deletions gain a $0.91 \%$ abnormal return at the 5 th day following ED, which passes through significant test. Meanwhile, additions make a $0.21 \%$ CAR but its index effect performance is weaker than deletions obviously.

(4) The curves for additions and deletions have a strongly symmetry and emerge reversal around AD, which conforms the price pressure hypothesis. This hypothesis can explain the price effect of the SHSZ 300 Index.

(5) Compared to traditional single-market index, the SHSZ 300 Index shows significant index effect and a lot of advantages, while it still has a big gap compared with the mature markets.

(6) Chinese market has shown index effect, but it is still weaker than the mature market. One important reason for this is our development of indexation investment is not sufficient and financial product innovation is lagging behind. Along with popularity of index funds, the SHSZ 300 Index will gain more market recognition and notice, and the amount of tracking money for the SHSZ 300 Index will increase accompanied by the investing of index at the same time. Therefore, we believe that the SHSZ 300 index effect will become more and more mature.

\subsection{Suggestions}

As China is an emerging market with significant transitional features, such as rapidly expansion of the market, low-proportion of shares holding of institutional investors, complex ownership structure of listed companies, as well as price manipulation occurring occasionally, it is important to study further and adjust constituent stocks in time in index management, which directly affects performance and transaction cost of index funds, as well as tracking error and risk arbitrage. Then this will affect the index development of products and marketing. Therefore, it is necessary for index fund managers to strengthen the research and forecasting of the SHSZ 300 Index with public information. Moreover, the index committee should give full play to coordinate the market, go on studying the constituent stocks, and select constituent stocks more carefully in terms of company foundation, industry representation and distribution of holdings. Monitor should also be strengthened at the same time. Furthermore, the relevant regulatory authorities should continue to promote and popularize the concept of index-based investment and further promote the SHSZ 300 Index futures and other innovative products.

\section{References}

Beneish, M. D., \& Gardner, J. C. (1995). Information costs and liquidity effects from changes in the Dow Jones Industrial Average list. Journal of Financial and Quantitative Analysis, 30, 135-157. http://dx.doi.org/10.2307/2331257

Beneish, M. D., \& Robert, E. W. (2002). S\&P 500 index replacements: A new game in town. The Journal of Portfolio Management, 29, 51-60. http://dx.doi.org/10.3905/jpm.2002.319863

Brealey, R. A. (2000). Stock prices, stock indexes and index funds. Bank of England Quarterly Bulletin, 1, 61-68.

Breazeale, J. P., \& Cuny, C. J. (2002). Stock price effects of changes in the S\&P Midcap 400 and the S\&P Smallcap 600 Indices. Working Paper.

Chen J. A., \& Jiang, W. (2012). Empirical Study of the index effect for the SHSZ 300 Index. China Foreign, 3,205-206.

Deininger, C., Kaserer, C., \& Roos, S. (2000). Stock price effects associated with index replacement in Germany. Working paper.

Elayan, F., Li, W., \& Pinfold, J. (2001). Price effects of changes to composition of New Zealand share indices. The New Zealand Investment Analyst, 3, 25-30.

Harris, L., \& Gurel, E. (1986). Price and volume effects associated with changes in the S \& P500 list: New evidence for the existence of price pressures. Journal of Finance, 41, 815-829. http://dx.doi.org/10.1111/j.1540-6261.1986.tb04550.x 
Liu, B. C. (2004). Empirical analysis on Shanghai stock market's index effect. Heilongjiang's Foreign Trade, 4, 29-30.

Liu, W. J. (2012). Theoretical analysis and empirical analysis of the index effect in the SHSZ 300 Index (Unpublished master's thesis, Department of Finance, Qingdao University, Qingdao, China). Retrieved from http://epub.cnki.net/kns/brief/default_result.aspx

Lynch, A. W., \& Mendenhall, R. R. (1997). New evidence on stock price effects associated with changes in the S\&P 500Index. Journal of Business, 3, 351-383. http://dx.doi.org/10.1086/209722

Qiu, X. F., \& Xu, J. G. (2003). Price effects and trading volume of the $\mathrm{t}$ constituent stocks in adjustment. Working paper. Retrieved from http//www.cfrn.com.cn/paper/paper_inf.php?paperid=502.

Shen, H. P. (2012). Empirical analysis of the index effect in the SHSZ 300 Index: Based on event study (Unpublished master's thesis, Economics and Management of Nanjing University of Aeronautics and Astronautics, Nanjing, China). Retrieved from http://epub.cnki.net/kns/brief/default_result.aspx

Shleifer, A. (1986). Do demand curves for stocks slope down. The Journal of Finance, 3, 579-590. http://dx.doi.org/10.1111/j.1540-6261.1986.tb04518.x

Song, F. M., \& Wang, C. Y. (2005). Index effect study on SSE 180 Index and SZSE. Securities Market Herald, 6 , 33-36.

Wang, X. Y. (2006). Empirical study of the index effect of the SSE 50 Index (Unpublished master's thesis). Foreign Economic and Trade University, Beijing, China.

Yuan, K. (2010). Theoretical and empirical review the SHSZ 300 Index constituent stocks to adjust the price effect. Capital Markets, 8, 47-51.

Zhang, J. G., \& Zhang, W. (2007). SSE 180 Index Effects empirical research. Journal of Beijing University of Aeronautics and Astronautics, 3, 14-17.

\section{Copyrights}

Copyright for this article is retained by the author(s), with first publication rights granted to the journal.

This is an open-access article distributed under the terms and conditions of the Creative Commons Attribution license (http://creativecommons.org/licenses/by/3.0/). 